\title{
New job economies and old pay gaps: Pay expectations explain the gender pay gap in gender-blind workplaces
}

Authors: Francesca Manzi ${ }^{1}$, Zohn Rosen ${ }^{2}$, Cheskie Rosenzweig ${ }^{3,4}$, Shalom N. Jaffe ${ }^{3,5}$, Jonathan Robinson $^{3,6}$, Leib Litman ${ }^{3,5 *}$

\section{Affiliations:}

${ }^{1}$ Department of Social, Health, and Organisational Psychology, Utrecht University; Utrecht, Netherlands

${ }^{2}$ Department of Health Policy \& Management, Mailman School of Public Health, Columbia University; New York, New York, United States of America

${ }^{3}$ Prime Research Solutions; Queens, New York, United States of America

${ }^{4}$ Department of Clinical Psychology, Columbia University; New York, New York, United States of America

${ }^{5}$ Department of Psychology, Lander College; Flushing, New York, United States of America

${ }^{6}$ Department of Computer Science, Lander College; Flushing, New York, United States of America

*Corresponding author. Email: leib.litman@touro.edu

\begin{abstract}
Despite the absence of many traditional barriers to gender equality, there continues to be a gender pay gap in new job economies (i.e., the "gig economy" or "platform work"). Taking a novel approach to the study of the gender pay gap, we use a completely gender-blind online work setting to examine the effect of a covert source of gender inequality: differential pay expectations. Our findings reveal that women's lower pay expectations lead to lower earnings. Crucially, these differential pay expectations appear to be shaped by income disparities in the traditional job economy. This research provides important new insight into the endurance of the gender pay gap, suggesting that structural inequities can carry over to new economies in subtle, yet powerful ways.
\end{abstract}




\section{Main Text:}

The gender pay gap is a persistent and pervasive problem. Although differences in earnings between women and men have slowly narrowed in many industrialized nations, they have remained relatively stagnant in the United States, hovering around $20 \%$ for the last two decades (1). Much previous research has attempted to understand the reasons behind this gap, identifying several structural, interpersonal, and individual-level factors that, taken together, result in lower wages for women than men (e.g., occupational segregation, gender-based discrimination, lack of access to child/elderly care services, differences in human capital, experience, and career choices; 2-6).

Teasing apart the unique effects of these different factors on the gender pay gap has long been difficult; in the traditional labor market, structural, interpersonal, and individual-level factors are deeply intertwined. However, the rapid rise of new job economies provides a novel opportunity to answer these longstanding questions and to do so in a naturally occurring work setting.

Also known as "gig economies," "sharing economies," and "platform work," new job economies are characterized by flexible, task-based, online platform-facilitated work. Jobs performed in these economies typically consist of small tasks that range from running errands (e.g., TaskRabbit), to selling products (e.g., eBay), to driving passengers (e.g., Uber), to participating in market research (e.g., Amazon Mechanical Turk). The Bureau of Labor Statistics has estimated that up to $43 \%$ of the US workforce participates in new job economies to some extent, and the industry is predicted to grow more than $17 \%$ annually (7). Notably, these figures predate the COVID-19 pandemic, and participation in this sector may have been further accelerated by consequent employment loss and restrictions in the traditional labor market $(8)$.

Although the non-traditional work arrangements that characterize new job economies were not specifically developed with the aim of ensuring workplace equity, new economy jobs nonetheless often lack many of the structural and interpersonal elements that have long contributed to the gender pay gap in the traditional labor market. As a result, new job economies may offer novel opportunities for greater pay equality. Compared to the traditional labor market, new job economies are much more flexible: Workers can often perform their tasks remotely, set their own schedules, and determine the number of hours they wish to work (9). Research suggests that flexible schedules and remote work should improve women's opportunities and decrease the gender pay gap (10). In addition, the processes involved in reward allocation, as well as the parameters for recruitment, selection, and promotion in new economies, are typically pre-established and do not rely on interactions between workers and employers (11). Strategies aimed at reducing gender-based bias often highlight the importance of such unambiguous, standardized job practices, given that these practices have been shown to decrease bias in decision making and salary negotiations (12). But perhaps the most groundbreaking and promising difference between new and traditional economies is that, in some of these new workplaces, a worker's gender is unknown. That is, while a worker's output is available to employers and/or clients, their identity is not. By effectively ruling out the possibility of genderbased discrimination on the part of employers and clients, this feature alone should dramatically decrease gender pay inequality.

Yet, challenging past research and theory, the gender pay gap persists in new job economies: Much like in the traditional economy, women have been found to earn less than men for comparable work (13-15), even in completely gender-blind online platforms (16). 
However, the reasons for the persistence of this gender pay gap - even in the absence of traditional drivers of gender inequality - remain unknown. Why does a gender pay gap emerge even when workers are free to choose from a wide variety of tasks, earnings are pre-established, work hours are flexible, and, most importantly, gender discrimination is taken out of the equation?

Here, we examine this question. We anticipated that the answer may lie in an important, yet understudied, consequence of systematic gender inequality in the traditional labor market: differential pay expectations. Pay expectations - that is, the amount of money that an individual expects to receive for their work - are shaped by numerous factors, including past earning experience and information about the earnings of similar others (17). In the traditional labor market, women's salary expectations for a given job are lower than those of men, and reliable gender differences have been found across several dimensions of pay expectations including entry-level salary, peak-career salary, and the minimum amount of pay for which women and men are willing to work (17-25).

Critically, there is evidence suggesting that gender differences in pay expectations can translate into actual disparities in pay (20). In the traditional labor market, women's lower pay expectations correlate with lower salary offers and fewer pay raises, and these differences persist even when adjusting for position and experience $(21,22)$. The role of differential pay expectations in earning differences between women and men has also been shown in laboratory studies, where participants actively decide how much money they should receive for their work. When performing the exact same task - and even when outperforming men - women were found to pay themselves less than men (23-25).

We predicted that differential pay expectations formed in the traditional labor market would covertly carry over to new economies, thereby explaining the emergence of this new gender pay gap. We tested this prediction on Amazon Mechanical Turk, a fully anonymous, gender-blind, online work platform. All work offered on the platform is conducted remotely: Employers post tasks on a virtual dashboard, and workers select and complete tasks for pay from their computers or mobile phones. To ensure anonymity, each worker is identified only by a unique, platformgenerated "worker ID" consisting of a random string of numbers and letters. Workers are free to choose from a large range of tasks, including image categorization, website testing, transcription, and participation in academic or market research. Among the information that is provided for each task is a title (e.g., "data entry"), a brief description (e.g., "short categorization task"), and the expected completion time (e.g., 20 minutes). Critically, the amount paid is pre-established and available to workers before selecting the task. Workers are typically paid shortly after completing each task (26).

Data for this study were obtained from 11,308 workers ( $46 \%$ women) who had collectively completed a total of 6.83 million tasks. To measure workers' pay expectations we used a question adapted from past research: "What is the absolute minimum take-home hourly wage below which you would not be prepared to work in any job?" (27). To examine the effect of systematic pay gender inequality in the traditional labor market, we asked participants to report their overall annual income. Hourly platform wages were calculated based on compensation per task (in dollars, as posted on the dashboard) divided by time required to complete the task.

We tested the association between worker gender, overall annual income, pay expectations, and hourly platform wages using OLS linear regression-based modeling. Consistent with our predictions, a gender pay gap emerged both in workers' overall annual salaries and in their 
hourly platform wages. Specifically, women's annual salary $(M=\$ 53.3 \mathrm{~K})$ was significantly lower than men's $(M=\$ 56.7 \mathrm{~K}), R=.05, F(4,11,434)=26.6, P<.001$, and women earned significantly less per hour on the online platform $(M=\$ 6.60)$ than did men $(M=\$ 6.87), R=.19$, $F(4,11,434)=107, P<.001$. There also was a $7.9 \%$ gender difference in pay expectations, whereby women's pay expectations $(M=\$ 12.95)$ were significantly lower than those of men $(M$ $=\$ 14.01) ; R=.29, F(4,11,434)=257, P<.001$. Critically, despite originating in the traditional labor market, pay expectations significantly predicted hourly wages in this gender-blind platform, $R=.03, F(4,11,434)=8.9, P=.003$. All analyses remained statistically significant when established predictors of the gender pay gap such as age, education, and number of children were included as covariates (16).

We next tested our central hypothesis - namely, that gender disparities in income in the traditional labor market lead to differential pay expectations, which in turn give rise to the gender pay gap in new economies. To test this hypothesis, we used a serial mediation model to determine whether annual income and pay expectations sequentially mediate the relationship between gender and hourly platform wages (see Fig. 1). Age, education, and number of children were again included as covariates in the model. Analyses revealed that, as predicted, the indirect path from gender to platform hourly wages was significantly mediated by overall annual income and pay expectations. Specifically, women's lower annual income predicted lower pay expectations, which in turn negatively predicted their earnings on the platform. Further supporting the crucial role of pay expectations in driving the online platform's gender pay gap, the direct effect of gender on hourly platform wages was not significant, indicating full mediation (see Table 1).

This work provides the first insight into what drives the gender pay gap in new gender-blind economies, revealing that differential pay expectations are a crucial, yet invisible force perpetuating wage differences between women and men. Although conducted in a new economy work setting, this research has important implications for increasing pay equality in both new and traditional economies alike-particularly as remote work and flexible hours become increasingly common in the traditional labor market. Our findings strongly suggest that interventions aimed at reducing the gender pay gap should focus on disrupting gender differences in pay expectations. Importantly, as new economy jobs represent the most rapidly growing employment sector (accounting for more than \$1.4 Trillion dollars in earnings in 2018 alone; 28), effectively addressing gender pay inequity early in the maturation of this sector might help to prevent billions of dollars in lost earnings for women.

More generally, these findings attest to the insidiousness of systematic gender inequality: They demonstrate that even when structural, interpersonal, and individual-level drivers of the gender pay gap are absent from the workplace, long-standing pay inequities can continue to hinder the value of women's work via lower pay expectations.

\section{References and Notes}

1. P. England, A. Levine, E. Mishel, Progress toward gender equality in the United States has slowed or stalled. Proceedings of the National Academy of Sciences. 117, 6990-6997 (2020).

2. F. D. Blau, L. M. Kahn, The gender wage gap: Extent, trends, and explanations. Journal of Economic Literature. 55, 789-865 (2017).

3. A. Levanon, D. B. Grusky, The persistence of extreme gender segregation in the twenty-first century. American Journal of Sociology. 122, 573-619 (2016). 
4. M. G. Alkadry, L. E. Tower, Unequal pay: The role of gender. Public Administration Review. 66, 888-898 (2006).

5. C. Goldin, A grand gender convergence: Its last chapter. American Economic Review. 104, 1091-1119 (2014).

6. A. Joshi, J. Son, H. Roh, When can women close the gap? A meta-analytic test of sex differences in performance and rewards. Academy of Management Journal. 58, 1516-1545 (2015).

7. International Labour Organization, "Helping the gig economy work better for gig workers" (2020, https://www.ilo.org/washington/WCMS 642303/lang-en/index.htm\#: : text $=$ The $\% 20$ Bureau $\% 20$ of $\% 20$ Labor $\% 20$ Statistics, to $\% 2043 \% 20$ percent $\% 2$ 0in\%202020).

8. Forbes, "Gig Economy And Micro-Entrepreneurship Are On The Rise, But Are We Ready To Manage That Successfully?" (2020, https://www.forbes.com/sites/forbestechcouncil/2020/10/20/gig-economy-and-microentrepreneurship-are-on-the-rise-but-are-we-ready-to-manage-that-successfully).

9. L. Litman, J. Robinson, "Conducting a Study on Mechanical Turk" in Conducting Online Research on Amazon Mechanical Turk and Beyond (SAGE, 2020), pp. 48-78.

10. European Institute for Gender Equality, "Flexible Working Arrangements" (2020, https://eige.europa.eu/publications/gender-equality-index-2019-report/flexible-workingarrangements\#: : text $=$ Flexible $\% 20$ working $\% 20$ arrangements $\% 20$ can $\% 20$ increase, working $\%$ 20schedules\%20in $\% 20$ Member $\% 20$ States).

11. V. De Stefano, The Rise of the 'Just-in-Time Workforce': On-Demand Work, Crowd Work and Labour Protection in the 'Gig-Economy'. Comparative Labor Law \& Policy Journal. 37, 461-471 (2015).

12. M. E. Heilman, S. Caleo, Combatting gender discrimination: A lack of fit framework. Group Processes \& Intergroup Relations, 21, 725-744 (2018).

13. C. Cook, R. Diamond, J. Hall, J. A. List, P. Oyer, The gender earnings gap in the gig economy: Evidence from over a million rideshare drivers. National Bureau of Economic Research (2018).

14. T. Kricheli-Katz, T. Regev, How many cents on the dollar? Women and men in product markets. Science Advances. 2, E1500599 (2016).

15. A. R. Barzilay, A. Ben-David, Platform inequality: gender in the gig-economy. Seton Hall L. Rev., 47 (2016).

16. L. Litman, J. Robinson, Z. Rosen, C. Rosenzweig, J. Waxman, L. M. Bates, The persistence of pay inequality: The gender pay gap in an anonymous online labor market. PloS One. 15, E0229383 (2020).

17. B. Major, E. Konar, An investigation of sex differences in pay expectations and their possible causes. Academy of Management Journal. 27, 777-792 (1984).

18. S. Brown, J. Roberts, K. Taylor, The gender reservation wage gap: evidence from British panel data. Economics Letters. 113, 88-91 (2011). 
19. M. Hogue, C. L. Dubois, L. Fox-Cardamone, Gender differences in pay expectations: The roles of job intention and self-view. Psychology of Women Quarterly. 34, 215-227 (2010).

20. P. F. Orazem, J. D. Werbel, J. C. McElroy, Market expectations, job search, and gender differences in starting pay. Journal of Labor Research, 24, 307-321 (2003).

21. L. Babcock, M. Gelfand, D. Small, H. Stayn, "Gender differences in the propensity to initiate negotiations" in Social Psychology and Economics, D. De Cremer, M. Zeelenberg, J. K. Murnighan, Eds. (Mahwah, NJ, 2006), pp. 239-262.

22. N. Roussille, https://ninaroussille.github.io/files/Roussille_askgap.pdf (2020).

23. M. Hogue, J. D. Yoder, The role of status in producing depressed entitlement in women's and men's pay allocations. Psychology of Women Quarterly. 27, 330-337 (2003).

24. B. Major, "From social inequality to personal entitlement: The role of social comparisons, legitimacy appraisals, and group membership" in Advances in Experimental Social Psychology (Academic Press, Vol. 26, 1994), pp. 293-355.

25. L. T. O'Brien, B. Major, P. N. Gilbert, Gender differences in entitlement: The role of systemjustifying beliefs. Basic and Applied Social Psychology. 34, 136-145 (2012).

26. M. Buhrmester, T. Kwang, S. D. Gosling, Amazon's Mechanical Turk: A new source of inexpensive, yet high-quality data? Perspectives on Psychological Science. 6, 3-5 (2016).

27. University of Cape Town, Southern Africa Labour and Development Research Unit. “Khayelitsha Mitchell's Plain Survey 2000” (2000, http://www.datafirst.uct.ac.za).

28. "Gig Economy Index," (Hyperwallet, 2019; https://securecdn.pymnts.com/wpcontent/uploads/2019/04/Gig-Economy-April-19.pdf).

29. L. Litman, J. Robinson, T. Abberbock, TurkPrime.com: A versatile crowdsourcing data acquisition platform for the behavioral sciences. Behavior Research Methods. 49, 433-442 (2017).

30. A. F. Hayes, Introduction to mediation, moderation, and conditional process analysis: A regression-based approach. (Guilford, 2017). 


\section{Supplementary Materials}

\section{$\underline{\text { Analytic sample and measures }}$}

Survey and metadata were collected from Amazon Mechanical Turk (MTurk), an online platform where work is performed anonymously. The MTurk platform was designed so that additional functionality can be provided by third parties. CloudResearch (CR; formerly TurkPrime; 29) is one such add-on or third party. CR allows employers (also known as "requesters") to manage multiple research functions (e.g., applying sampling criteria, facilitating longitudinal studies) through a link to an MTurk worker's account. Thus, while workers' demographic information (e.g., gender, age, ethnicity) is not directly available to "requesters", we were able to access these data through CR's database. CR's metadata contains demographic information on virtually all MTurk workers as well as information on their work history.

The analytic sample consisted of 11,308 MTurk workers (46\% women) who provided an answer to our pay expectations measure between March and April of 2020. Specifically, workers were asked to respond to a question adapted from the Khayelitsha/Mitchell's Plain Survey (27), "What is the absolute minimum take-home hourly wage below which you would not be prepared to work in any job?". Relevant metadata was then obtained from the workers who completed this measure. Specifically, the CR database was queried to obtain worker demographics such as gender, age, level of education, and overall annual salary. Metadata for 6.83 million tasks were also obtained to calculate hourly platform wages for each worker. Hourly wages were calculated based on the time required to complete a task against compensation in dollars per task (as posted on the dashboard by the "requester").

\section{Analytic approach}

We evaluated the association between gender, hourly platform wages, overall annual income, and pay expectations using OLS linear regression-based modeling. We began by looking at simple bivariate associations between gender and the three outcome measures (hourly platform wages, overall annual income, and pay expectations). To address potential confounds with demographic variables known to predict earning differences (16), we modeled the association between gender and the three outcome measures with the inclusion of age, education, and the number of children in the family as covariates in the regression model.

Heteroskedasticity was controlled in all regression models, including mediation models, by using robust standard errors.

After examining whether gender was a predictor of hourly platform wages, overall annual income, and pay expectations, a serial mediation model was tested (see Figure 1). The main goals of this mediation model were to test for; 1) whether worker gender directly predicts hourly platform wages independent of the mediators (i.e. whether there is a direct effect of gender on hourly platform wages), 2) whether worker gender predicts hourly platform wages through overall annual income, 3) whether worker gender predicts hourly platform wages through pay expectations and 4) whether the mediating effect of overall annual income is, in turn, mediated by pay expectations (the predicted serial mediation model).

\section{Mediation Model}

Serial mediation was utilized to simultaneously examine three separate paths (see Figure 1). The first path (Path $\left.\mathrm{a}^{1} \mathrm{~d}^{1}\right)$ examines the indirect effect of worker gender on hourly platform wages through overall annual income. This model tests the hypothesis that female workers have lower overall annual incomes which in turn leads to lower hourly wages among women than men on 
the platform. The second path $\left(\right.$ Path $\left.^{1} \mathrm{a}^{3}\right)$ examines the indirect effect of worker gender on hourly platform wages through pay expectations. This model tests the hypothesis that female workers have lower pay expectations which in turn leads to lower hourly platform wages among women than men. The third and final path tests our main hypotheses $\left(\mathrm{Path}^{1} \mathrm{a}^{2} \mathrm{a}^{3}\right)$ by examining whether the indirect effect of gender on hourly platform wages is serially mediated by overall annual income and pay expectations. This model tests the hypothesis that female workers have lower annual incomes, which leads to lower pay expectations and, in turn, predicts lower hourly wages among women than men on the platform.

Multiple covariates were controlled for in the mediation model. Variables were included as covariates in the model if they could be reasonably expected to play a role in the relationship between gender and wages or were previously demonstrated to correlate with the gender wage gap on this platform (16). Covariates that were added to the model included age, education, and number of children in the family.

To test mediation effects, confidence intervals were generated by bootstrapping ( 5,000 iterations; see 30 ). The bootstrapping procedure tests the null hypothesis that the indirect path from the independent to the dependent variable via the mediators does not significantly differ from zero. If zero is not contained within the confidence intervals (CI) computed by the bootstrapping procedure, one can conclude that the indirect effect is significantly different from zero at $p<0.05$. In addition to the confidence intervals, $p$-values based on the Sobel method for evaluating the significance of an indirect effect were also utilized (see Table 1). 


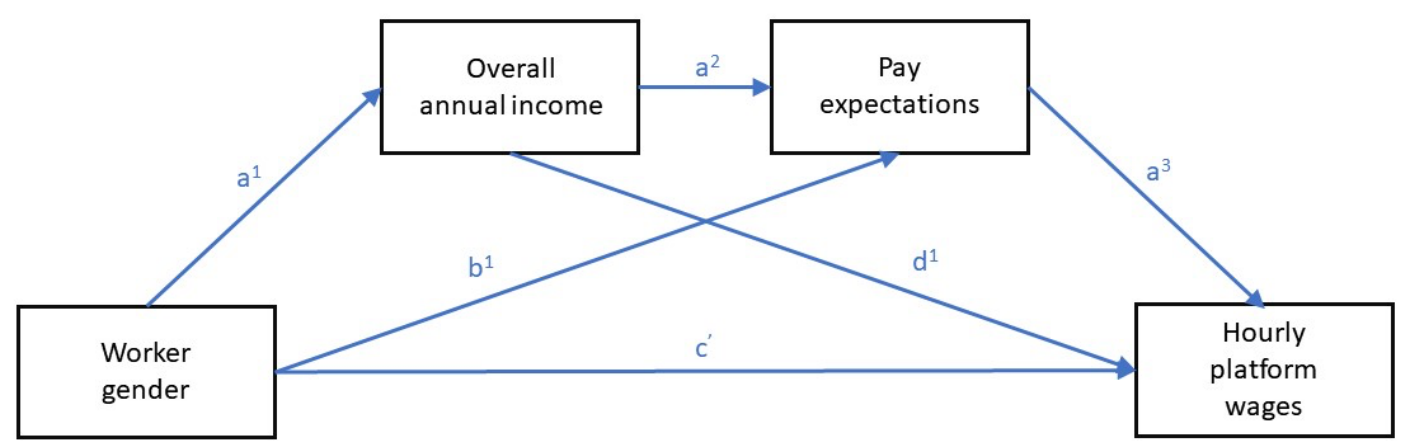

Fig. 1. Serial mediation model. Path $a^{1} a^{2} a^{3}$ is the full serial mediation path. Path $a^{1} d^{1}$ is the path from worker gender to hourly platform wages through overall annual income. Path $b^{1} a^{3}$ is the path from worker gender to hourly platform wages through pay expectations. Path $c$ ' is the direct path from worker gender to hourly platform wages.

Table 1. Serial mediation results. Mediation models examining the association between worker gender and hourly platform wages through overall annual income $\left(a^{l} d^{l}\right)$, pay expectations $\left(b^{1} a^{3}\right)$, and overall annual income and pay expectations $\left(a^{1} a^{2} a^{3}\right)$. Unstandardized B weights are shown for each model, the direct path $\left(c^{l}\right)$, and covariates.

\begin{tabular}{lcccc}
\hline & \multicolumn{4}{c}{ Y = Hourly platform wages } \\
\hline & $\mathbf{B}$ & $\mathbf{S E}$ & $\mathbf{p}$ & $\mathbf{C I}$ \\
\hline$a^{\prime} a^{2} a^{3}$ & & & & \\
$b^{\prime} a^{3}$ & .0027 & .0010 & $\mathrm{NA}$ & $.0011-.0048$ \\
$a^{\prime} d^{\prime}$ & .0181 & .0056 & $\mathrm{NA}$ & $.0079-.0298$ \\
$c^{\prime}$ & .0378 & .0078 & $\mathrm{NA}$ & $.0229-.0573$ \\
Age & .0691 & .0645 & .28 & $-.0573-.1955$ \\
Children & .0320 & .0026 & $<.001$ & $.0270-.0371$ \\
Education & .1898 & .0286 & $<.001$ & $.2458-.1338$ \\
\hline
\end{tabular}

